\title{
Perspective
}

PERSPECTIVE Actualité en histoire de l'art

Comptes rendus | 2008

\section{Jean-Maurice Rouquette et al. éd., Arles : histoire, territoires et cultures, Paris, Actes Sud, 2008}

\section{Thomas Creissen}

\section{(2) OpenEdition}

\section{Journals}

Édition électronique

URL : http://journals.openedition.org/perspective/3324

DOI : 10.4000/perspective.3324

ISSN : 2269-7721

Éditeur

Institut national d'histoire de l'art

Référence électronique

Thomas Creissen, « Jean-Maurice Rouquette et al. éd., Arles : histoire, territoires et cultures, Paris, Actes Sud, $2008 »$, Perspective [En ligne], Comptes rendus, mis en ligne le 02 septembre 2013, consulté le 01 octobre 2020. URL : http://journals.openedition.org/perspective/3324 ; DOI : https://doi.org/10.4000/ perspective.3324

Ce document a été généré automatiquement le 1 octobre 2020. 


\section{Jean-Maurice Rouquette et al. éd., Arles : histoire, territoires et cultures, Paris, Actes Sud, 2008}

Thomas Creissen

\section{RÉFÉRENCE}

Jean-Maurice Rouquette et al. éd., Arles : histoire, territoires et cultures, Paris, Actes Sud, 2008. 
Cet ouvrage n'est pas à proprement parler une publication scientifique - il n'a pas d'appareil de notes - mais il se révèle néanmoins d'une grande utilité. Après une présentation très concise et fort bien illustrée de la période qui va de la préhistoire jusqu'à l'Antiquité classique, deux parties traitent respectivement consacrées de l'Antiquité tardive et de l'émergence de l'Église d'Arles. Les contributions de Jean Guyon et Marc Heijmans sont claires et bien documentées, et le chapitre consacré au $\mathrm{IV}^{\mathrm{e}}$ siècle est l'occasion de revenir sur

l'extraordinaire collection de sarcophages paléochrétiens conservés en Arles. Jusqu'au $\mathrm{VI}^{\mathrm{e}}$ siècle, les données archéologiques combinées aux sources textuelles permettent de proposer une vision assez parlante de la topographie chrétienne de la ville ainsi que de sa réalité monumentale et artistique. Par la suite, la situation est bien moins satisfaisante. Les chapitres de Marc Heijmas - «Vers le haut Moyen Âge »- et de Martin Aurell - «Arles à l'époque carolingienne et féodale » - sont essentiellement historiques et les données relatives à la production artistique restent peu nombreuses en dehors des propositions de datation: comme pour Saint-Sernin, il est dès lors difficile d'établir un lien entre les monuments romans et leurs prédécesseurs immédiats. Jean-Maurice Rouquette est l'auteur de la partie consacrée à l'histoire d'Arles correspondant à la diffusion de l'art roman (« Des comtes de Barcelone à la maison d'Anjou »). Sa présentation est complexe, et il est parfois difficile de bien comprendre les évolutions de la ville en l'absence de documents graphiques, notamment de cartes. Les monuments et leur décor ressortissant à cette période sont ensuite évoqués par Andreas Hartmann-Virnich («L'architecture romane religieuse à Arles »). La faible place - une dizaine de pages - accordée à l'analyse d'un ensemble assez riche fait que celui-ci n'est pas abordé de manière poussée. Dans le domaine de l'architecture, l'auteur souligne l'existence de quelques entreprises pionnières au cours $\mathrm{du} \mathrm{xI}^{\mathrm{e}}$ siècle (Saint-Pierre de Montmajour et la nef de Saint-Honorat des Alyscamps sont rapidement évoqués), mais c'est toutefois le XII ${ }^{\mathrm{e}}$ siècle qui marque le véritable envol de l'architecture et du décor sculpté. Peut-être planifié dès la fin du XI ${ }^{\mathrm{e}}$ siècle, le chantier de reconstruction de Saint-Trophime ne démarre que dans le deuxième quart du XII siècle. Ce chantier est présenté de manière essentiellement descriptive, parti également privilégié pour évoquer d'autres entreprises contemporaines (chevet de Saint-Honorat, Saint-Blaise, Notre-Dame de Montmajour). La sculpture, quant à elle, est abordée à travers le portail de Saint-Trophime, qui se rattache à la décennie 1180-1190. Dans ces mêmes années semble avoir été exécutée une partie du décor sculpté du cloître de la cathédrale. L'analyse de cette sculpture est rapide: pour l'essentiel, Andreas Hartmann-Virnich est contraint de se limiter à une description des principaux thèmes mis en image. En définitive, l'architecture comme la sculpture romane d'Arles et de son territoire sont abordées ici d'une manière superficielle. 